\title{
A simple method for preparing elemental selenium nano-coating inside a silicone surface
}

\author{
Khandsuren Badgar ${ }^{1,2}$ - József Prokisch ${ }^{1,2}$ \\ ${ }^{1}$ Institute of Animal Science, Biotechnology and Nature Conservation, Faculty of Agricultural and Food Sciences and Environmental \\ Management, University of Debrecen, 138 Böszörményi Street, 4032 Debrecen, Hungary \\ ${ }^{2}$ Doctoral School of Animal Science, University of Debrecen, 138 Böszörményi Street, 4032 Debrecen, Hungary \\ b_khandsuren@muls.edu.mn
}

\begin{abstract}
SUMMARY
Selenium nanoparticles (SeNPs) with a bright red colour have aroused worldwide attention due to their unique properties in selenium supplementation because of their low toxicity and favourable bioavailability. A simple method was developed for making a red selenium nanolayer on the inner surface of Polyvinyl chloride (PVC) and silicone tube. The selenium nanoparticles were produced by the reaction of sodium selenite and ascorbic acid. Red amorphous selenium nanoparticles have been successfully synthesized by the reaction of 500 mg dm ${ }^{-3}$

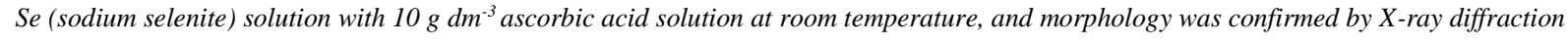
analysis (XRD). The coating density was compared on PVC and silicone surfaces by using Scanning Electron Microscopy (SEM) and Energydispersive X-ray (EDS) analysis. The nanolayer with about $16 \mu$ m thickness on the silicone surface significantly evenly distributed compared to the PVC surface. The selenium coated silicone tube could be a good source of selenium for a continuous, low-level selenium supplementation of farm animals via drinking water.
\end{abstract}

Keywords: selenium nanoparticles (SeNPs); synthesis; coating; silicone tube; PVC

\section{INTRODUCTION}

Selenium is an essential microelement that supports health maintenance and disease prevention of humans and animals as a major structural component of some important enzymes and hormones. Generally, its nutritional value depends mainly on the dose and type of selenium species present in the source. The elemental selenium nanoparticles have very good bioavailability (Shi et al., 2011; Wang et al., 2007; Zhang et al., 2008), and low toxicity (Benko et al., 2012; Zhang et al., 2008). On the other hand, the biological properties and applications depend on the process of preparation. Especially smaller particles have greater activity (Torres et al., 2012). Therefore, in recent years, the synthesis of nanoparticles is increasingly focusing being focused upon. The synthesis of nanoparticles occurs through the reduction of metal ions to neutral metal atoms by the addition of reducing agents such as by biological (plant, bacteria, fungi, protozoa), physical (sonication, laser ablation, radiation, electro-deposition), and chemical (sol-gel technologies, redox processes, hydrothermal) sources. That way, the size, shape, structure, and atomic arrangement of nanomaterials change, and they have high bioavailability and lower toxicity than other general forms. Therefore, nanoparticles play an important role in a lot of applications related to biomedical engineering, chemical technology, environmental engineering, polymer technology, biotechnology, food science, agricultural development, etc. (Prasad et al., 2017; Ram et al., 2014). Especially, selenium nanoparticles have recently attracted more attention in many scientific sections, and selenium has been widely used in food supplements and nanomedicine. Because, selenium nanoparticles have functional properties for treatments and preventions which play in the feed digestibility (Galbraith et al.,
2016; Shi et al., 2011; Xun et al., 2012), reproductive system (Badade \& Narshetty, 2011; Fernandes et al., 2012; Shi et al., 2010), antioxidant system (Shi et al., 2011; Wang et al., 2007), immune systems (Kojouri et al., 2012), anticancer (Bao et al., 2015; Pi et al., 2013; Ramamurthy et al., 2013; Zhang et al., 2013), antibacterial (Jackman et al., 2016; Shoeibi \& Mashreghi, 2017; Sonkusre \& Cameotra, 2015; Srivastava \& Mukhopadhyay, 2015), and intoxication processes (Trabelsi et al., 2013). Many types of bacteria are able to convert inorganic selenium to nanoparticle form, and various bacterial species especially probiotic bacteria have been employed by different authors (Cruz et al., 2018; Fesharaki et al., 2010; Kora \& Rastogi, 2017; Lampis et al., 2014). We already developed and patented a technology to produce nano-size (100-500 $\mathrm{nm})$ elemental selenium by using probiotic bacteria in a fermentation procedure. The technique is the first to use Lactic acid bacteria and other probiotic bacteria (Species of Lactobacillus and Bifidobacteria, Streptococcus thermophilus) to form the product, selenium nanospheres. The main advantage of the process makes possible the production of uniform nanospheres in a specific size of 50-500 nanometers (with 5-20\% standard deviation) in diameter depending on the species used for the fermentation (Prokisch \& Zommara, 2011). In this time, we tested a chemical method for the synthesis of selenium nanoparticle. Basically, chemical transformation is widely used technique for the production of the nanoparticle, especially the reduction methods (Horikoshi \& Serpone, 2013). Various biocompatible reducing agents such as L-cysteine (Li et al., 2010), D-fructose (Vieira et al., 2017), glucose (Chen et al., 2011), lactose (Cavalu et al., 2018), gallic acid (Stacey et al., 2013), ascorbic acid (Ashwini et al., 2019), etc. have been employed in the synthesis of selenium nanoparticles with various size and shape. In this study, we used 
ascorbic acid as a reducing agent. L-ascorbic acid is a vitamin $\mathrm{C}$ participating in several biochemical reactions and is a naturally available antioxidant. Its antioxidant effect is one of the best-known biological functions. It plays role in the repair of tissue and the enzymatic production of certain neurotransmitters and the immune system. Also, it has high water solubility, biodegradability, and low toxicity (Sun et al., 2009). Therefore, it has been used to the bioconversion of nanoparticles such as gold (Sun et al., 2009), silver (Qin et al., 2010), and selenium (Gangadoo et al., 2017).

$$
\mathrm{SeO}_{3}{ }^{2-}+2 \mathrm{H}^{+}+2{ }_{\mathrm{C}_{6} \mathrm{H}_{8} \mathrm{O}_{6}}^{\mathrm{HO}}
$$$$
\text { Ascorbic acid }
$$

\section{Coating of Selenium nanoparticles}

Freshly prepared selenium nanoparticles coated on the inner surface of the PVC tube and silicone tube at room temperature by using a peristaltic pump (Dr. Aliment Ltd, Kecskemét, Hungary) with 95 rpm for 30 minutes, and the colour of tubes changes from colourless to red colour.

\section{Characterization}

The colour-changing of the mixed solution of sodium selenite and ascorbic acid was tested by UV/VIS spectroscopy. The light absorption (light dispersion) was measured using Perkin Elmer Lambda $2 \mathrm{~S}$ double beam UV/VIS spectrophotometer on 400 $\mathrm{nm}$ at room temperature with $1 \mathrm{~cm}$ path-length quartz cuvette. Distilled water was used as a blank. With this method practically we measured the turbidimetric signal because the signal originated from the light scattering of solid particles, not from the light absorption. The initial solutions (selenite and ascorbic acid) have no absorption at $400 \mathrm{~nm}$, but the forming nanoparticles scattered the light and it can cause intensity decreasing.

The particle size and distribution of the produced selenium nanoparticles were measured by dynamic light scattering using a Malvern Mastersizer 2000 particle size analyser that works by using the optical bench to capture the actual scattering pattern form a field of particles. Finally, it calculates the size of particles that created the pattern.

XRD patterns of the nanoparticles were recorded with a SuperNova X-ray diffractometer (Rigaku Corporation, Tokyo, Japan) using a $\mathrm{Cu} \mathrm{K} \alpha$ source $(\lambda=0.15406 \mathrm{~nm})$. The surface morphology and composition analysed by Hitachi S-4300 Scanning electron microscope (SEM) and Energy-dispersive X-

\section{MATERIALS AND METHODS}

\section{Preparation of selenium nanoparticles}

A modified chemical reduction method was used. A stock of a $25 \mathrm{mg} \mathrm{dm}^{-3}$ to $500 \mathrm{mg} \mathrm{dm}^{-3}$ sodium selenite solution and $1 \mathrm{~g} \mathrm{dm}^{-3}, 5 \mathrm{~g} \mathrm{dm}^{-3}$, and $10 \mathrm{~g} \mathrm{dm}^{-3}$ ascorbic acid solution was prepared before 2 hours of the experiment. Sodium selenite and ascorbic acid solutions were mixed in a 1 to 1 volume ratio from stock solutions in the plastic tube at room temperature for 60 minutes. The mixtures were allowed to react with each other in the concentrated form until a colour change was observed from colourless to red colour.

The chemical reaction of the formation of nanoparticles $\left(\mathrm{Se}^{0}\right)$ is the following:

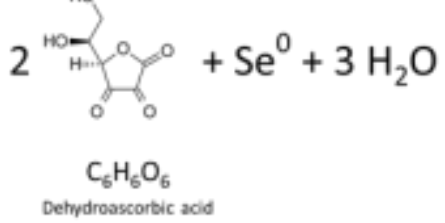

ray (EDS) analysis. PVC and silicone tube coated with selenium nanoparticles were rinsed by distilled water and dried at room temperature. Then small pieces were used to check the morphology, and thickness of the nanolayer.

\section{RESULTS AND DISCUSSION}

The reduction of sodium selenite was clearly confirmed through observation with the naked eye. The colour and hydrogen ion concentration $(\mathrm{pH})$ of the reaction was changed caused by concentrations of the selenium and ascorbic acid, and reaction time. Especially, the colour of the reaction within $10 \mathrm{~g} \mathrm{dm}^{-3}$ ascorbic acid and $500 \mathrm{mg} \mathrm{dm}^{-3}$ selenium was significantly changed from colourless to a red solution than other concentrations (Figure 1). It was obviously correlated to $\mathrm{pH}$ and this colour demonstrated reaction progression. The reduction process was faster in acidic environment $(\mathrm{pH}<7.0)$ with higher concentration of ascorbic acid. Mostly, the red colour is linked to amorphous spheres (Hageman et al., 2017). Ascorbic acid is often preferred as reducing agent due to its biocompatibility and low toxicity in the body compared to other reducing agents (Sun et al., 2009).

The most easily observed property of nanoparticles is their change in colour with different sizes as very often this colour is different in transparent and reflected light (Figure 2). So as the size changes, the colour of the particles formed will also change; scattering and absorption in the visible region of the spectrum. Thus, light scattering is the most basic technique for the identification and characterization of nanoparticles. 


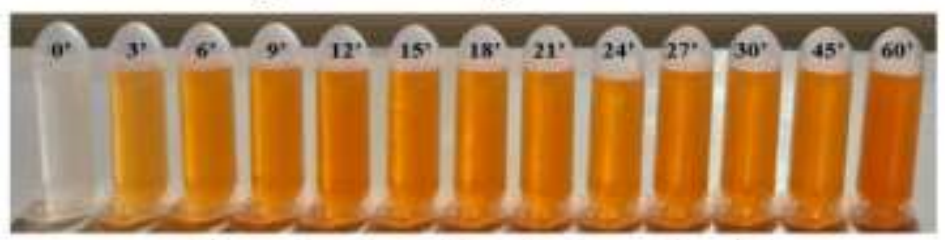

$500 \mathrm{mg} \mathrm{dm}^{35}$ Se and $10 \mathrm{~g} \mathrm{dm}^{-3}$ ascorbic acid

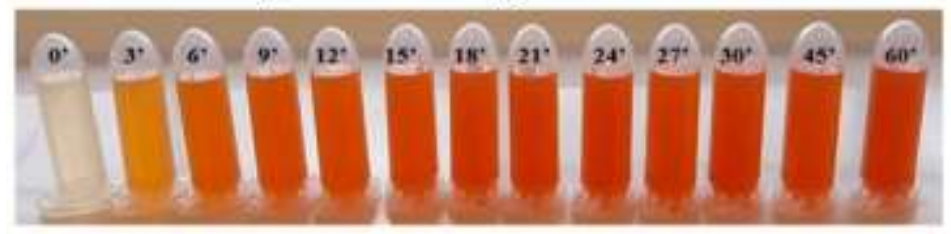

Figure 2. Red elemental selenium nanoparticles in transparent and reflected light

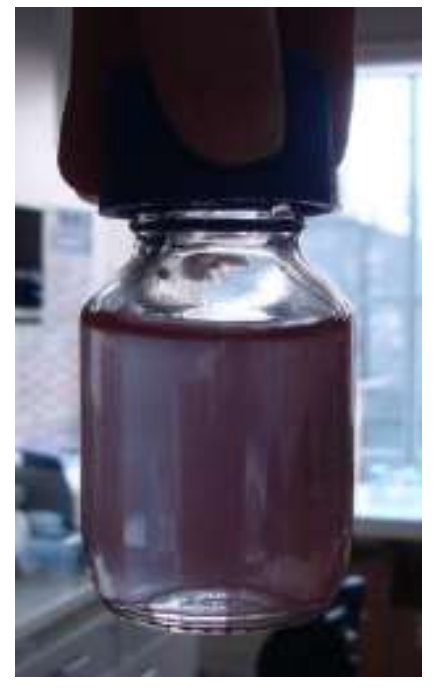

The UV/VIS absorption signal what is originated from the light scattering is shown at $400 \mathrm{~nm}$ in Figure 3. The absorption changing by time shows the rate of reaction, the formation of particles. Some study reported that an absorption maximum at $390 \mathrm{~nm}$ (Sonam et al., 2014), 395 nm (Prasad et al., 2013), 381$399 \mathrm{~nm}$ (Alam et al., 2019), $400 \mathrm{~nm}$ (Vyas \& Rana, 2018), 200-400 nm (Ramamurthy et al., 2013), and 420 $\mathrm{nm}$ (Sowndarya et al., 2017) were due to the formation of selenium nanoparticles by ascorbic acid, lemon extract, Psidium guajava, Allium sativum, fenugreek extract and Clausena dentate, respectively. Various reports have verified that the resonance peak of nanoparticles appears around this region, but the accurate position depends on several factors such as particle's size, shape, and material composition, as well as the local environment (Joshi et al., 2008). The reduction rate of $10 \mathrm{~g} \mathrm{dm}^{-3}$ ascorbic acid for each concentration of the sodium selenite was significantly higher than $1 \mathrm{~g} \mathrm{dm}^{-3}$ and $5 \mathrm{~g} \mathrm{dm}^{-3}$ ascorbic acid. For concentrations of sodium selenite, the absorption of
$500 \mathrm{mg} \mathrm{dm}^{-3}$ solution increased dramatically until 30 minutes of the reaction periods. In other words, solutions of $500 \mathrm{mg} \mathrm{dm}^{-3}$ sodium selenite and $10 \mathrm{~g} \mathrm{dm}^{-}$ ${ }^{3}$ ascorbic acid were appropriate to form the selenium nanoparticles. This may be the least suitable ratio for the synthesis of selenium nanoparticle liquid form because higher ratio, higher concentration of sodium selenite may cause precipitation. Different concentrations of sodium selenite as selenium precursor with lactose (Cavalu et al., 2018), L-cysteine (Li et al., 2010), and ascorbic acid (Ashwini et al., 2019; Sonam Malhotra et al., 2014) as a reducing agent have been used for the synthesis of selenium nanoparticle.

X-ray diffraction analysis of the synthesized selenium nanoparticles was shown in Figure 4. The XRD pattern of the red selenium sample was noisy and broader with no sharp. Thus, the data indicates the amorphous nature of the particles which is red in colour. These results are in agreement with other studies carried on chemical synthesis of selenium 
nanoparticles using reducing agents L-cysteine $(\mathrm{Li}$ et al., 2010), glucose (Chen et al., 2011), and D-fructose (Vieira et al., 2017). Also, these results were observed in biological synthesized selenium nanoparticles using bacterial strains Pseudomonas alcaliphila (Zhang et al., 2011), and Capsicum annuum extract (Li et al., 2007).

Figure 3. Reaction rate of selenium particles formation by using different concentration of selenite solutions $\left(25-500 \mathrm{mg} \mathrm{dm}^{-3}\right)$ measured at $400 \mathrm{~nm}$. The ascorbic acid concentration was $10 \mathrm{~g} \mathrm{dm}^{-3}$

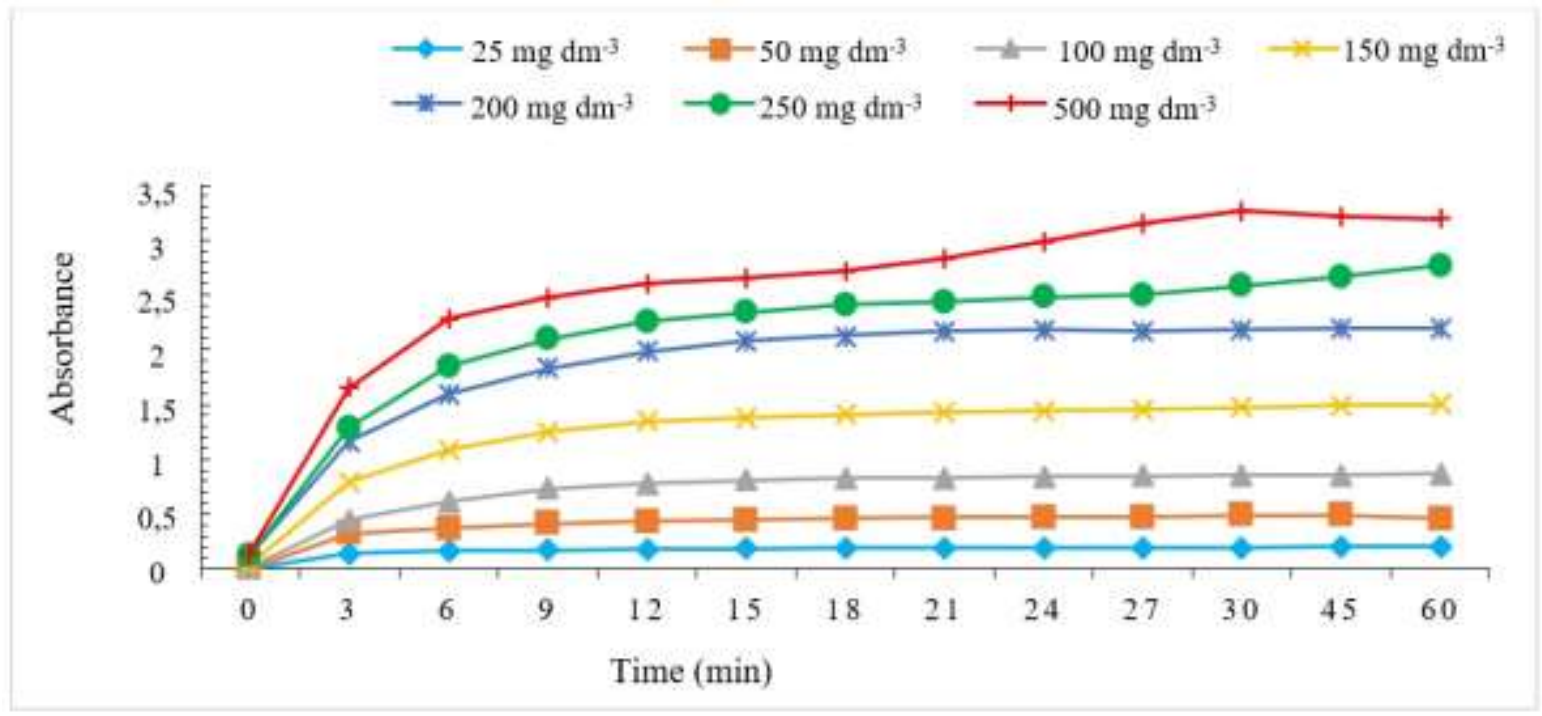

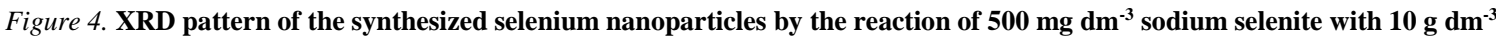
ascorbic acid

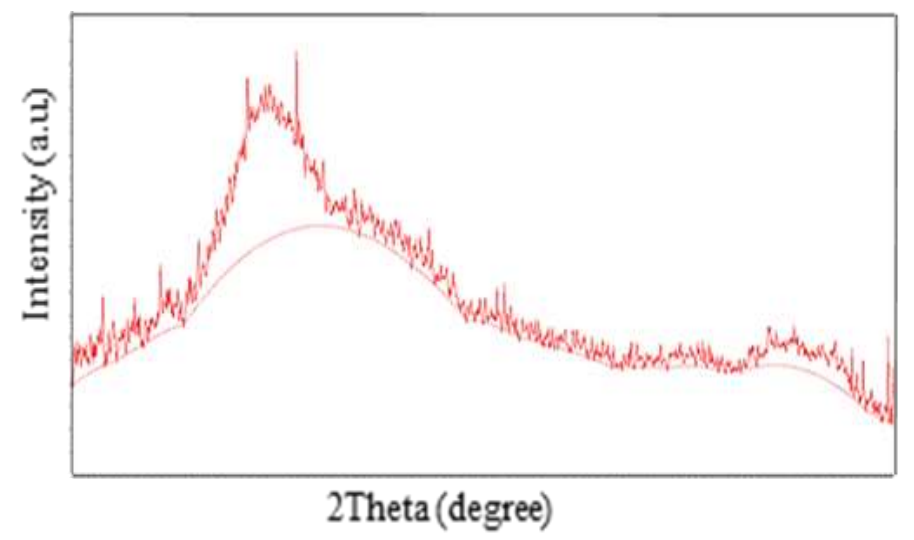

The particle size distribution of selenium nanoparticles produced by $500 \mathrm{mg} \mathrm{dm}^{-3}$ sodium selenite with $10 \mathrm{~g} \mathrm{dm}^{-3}$ ascorbic acid measured that nanoparticles having a size range of $50 \mathrm{~nm}$ to $100 \mu \mathrm{m}$. The colour change corresponds with the redshift in the absorbance peak that occurs when the amorphous nanospheres particle size increase from $0-18 \mathrm{~nm}$ to 220-240 nm (Lin \& Chris 2005). It indicated that smaller particles readily interact with each other to form larger particle sizes (Xiong \& Xia, 2007). We noticed an interesting phenomenon at the particle size measurement: the inner surface colour of the silicone tube (what is used for the circulation of the sample between the cuvette and sample holder) changed to red. So we decided to study the forming selenium layers on PVC and silicone tubes. These types of tubes are the most common plastic tubes in medicine, like infusion sets and others. We consider the biological effects of this selenium coating is worth to study in the future. In a liquid the selenium nanoparticles can aggregate to a large extent as it was noticed in the particle size analysis. Over time, the size of the aggregates grew, finally reached the $100 \mu \mathrm{m}$ in size (Figure 5). 
Figure 5. The change of particle size distribution of selenium nanoparticles measured by a particle size analyzer after the preparation. It shows the nano size selenium particles agglomerate in time. The different measurements were made after 10, 20 and 30 minutes of mixing ascorbic acid and selenite with continuous stirring
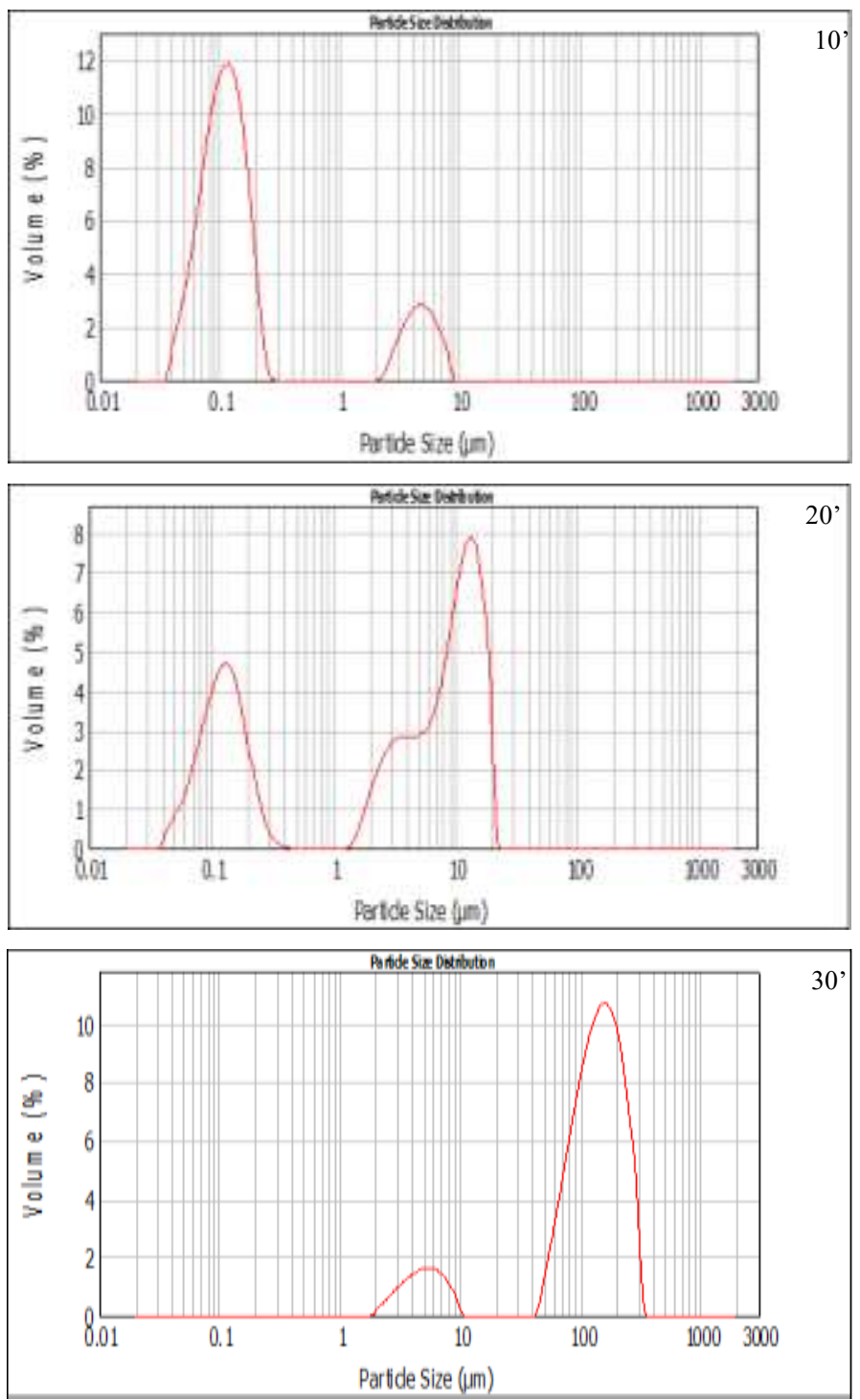

According to the experiments, we can summarize the simple production method of creating a nano selenium layer inside the silicone tube surface. The nanolayer can be made by circulating the freshly prepared selenium nanosuspension with a peristaltic pump with a speed of $1-10 \mathrm{~mL} / \mathrm{min}$ or $95 \mathrm{rpm}$ (Figure $6)$. After the stabilization of the red colour, it can be washed by distilled water.

The size and morphology of selenium nanoparticles (top-down) and thickness of nanolayer (cross section) were identified by scanning electron microscopic techniques. Also, Energy-dispersive X-ray spectra (EDS) were used to confirm the chemistry of the selenium nanoparticles. SEM images with EDS indicated the coating density of PVC and silicone covered with selenium nanoparticles. In results, EDS spectrum indicated that selenium peaks were detected in both tubes coated with selenium nanoparticles, which confirmed that the nanoparticles were in fact elemental selenium. The size of the produced particles indicated range about $100-200 \mathrm{~nm}$, but these individual particles attached to each other and make $2 \mu \mathrm{m}$ size aggregate spheres on the PVC surface (Figure $7 b$ and Figure $8 b$ ). The silicone surface was coated with a large amount of selenium nanoparticles. Also, these nanoparticles were well distributed on the silicone surface and covered almost all parts of the surface (Figure 7a). The silicone surface is covered with a selenium nanolayer of about $16 \mu \mathrm{m}$ thickness (Figure $8 a)$. 
Figure 6. Coating of silicone and PVC tube with red selenium nanoparticles by using a circulation of selenium suspension with a peristaltic pump


Figure 7. SEM images and X-ray spectra of selenium nanoparticles on the inner surface of silicone (a) and PVC (b). Elemental selenium (Se) peaks are detected in PVC and silicone surface coated with selenium nanoparticles. Peaks of chlorine (Cl) and silica (Si) present are from the PVC and silicone substrate; peaks of gold (Au) present are from the sputter-coating process
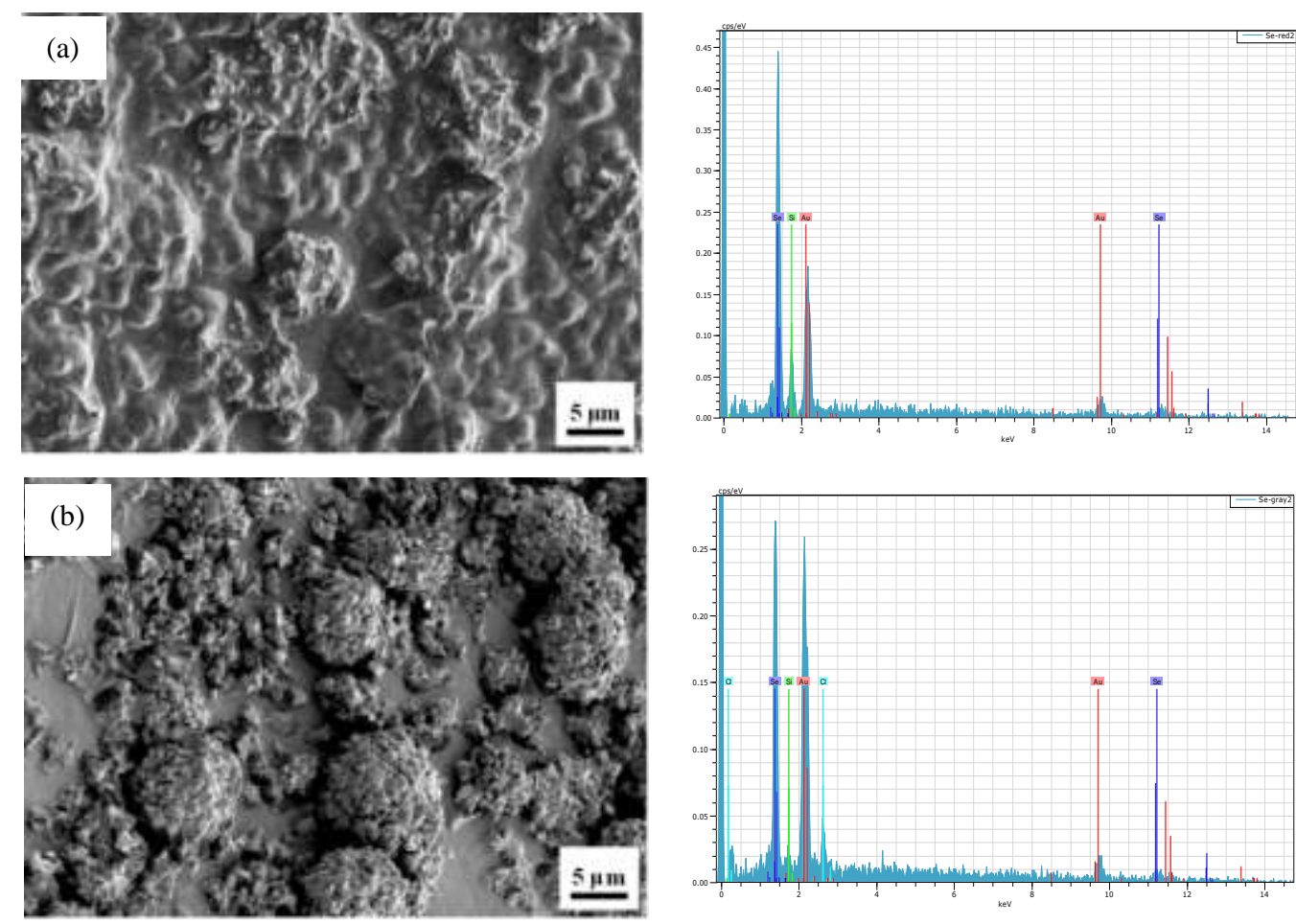

Figure 8. SEM images for a cross-sectional area of silicone (a) and PVC (b) surface coated with selenium nanoparticles
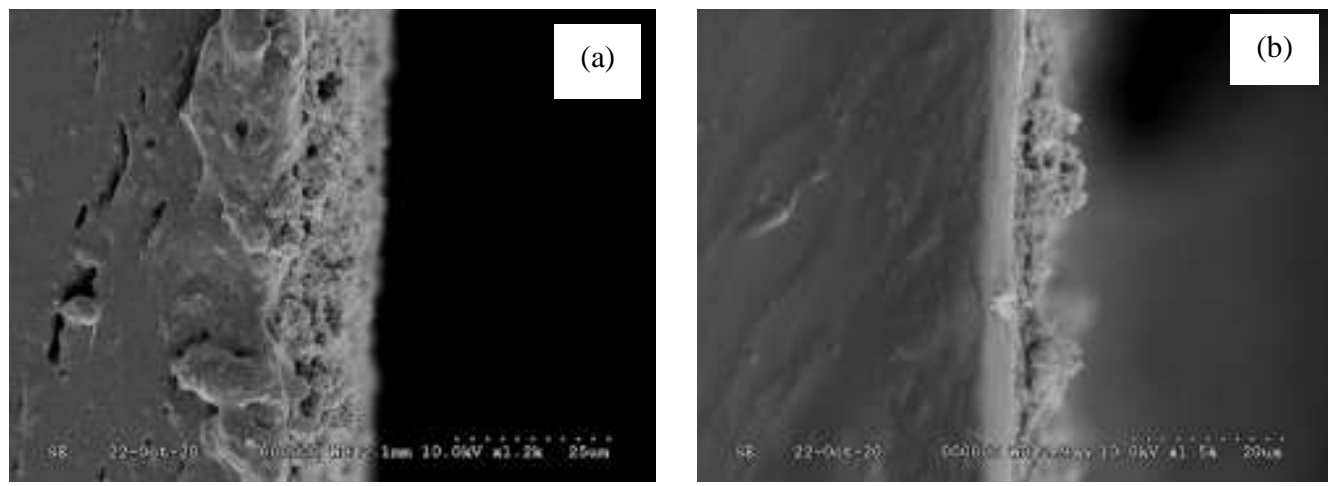


\section{CONCLUSIONS}

The synthesis of selenium nanoparticles was performed by the green chemistry route, using sodium selenite as selenium compound and ascorbic acid as a reducing agent in a bottom-up design synthesis approach. The proposed method is a simple, rapid, inexpensive, and one-step preparation for the fabrication of selenium nanoparticles suitable for biological applications such as food and feed supplements. We coated selenium nanolayer of about $16 \mu \mathrm{m}$ thickness on the silicone surface. The developed method is a simple, effective, and fast. The selenium coated silicone should be studied for the application of medical tools and tubes. The selenium coated tubes could be good for selenium supplementation of animals if this tube is inserted to the water system. The selenium will be released slowly from the surface of the tube by reduction or oxidation of elemental selenium to selenide or selenite.

\section{ACKNOWLEDGEMENTS}

The authors wish to thank Dr. Lajos Daróczy (Department of Solid State Physics. University of Debrecen) for help with the scanning electron microscopic pictures, and Dr. Attila Bényei, Department of Physical Chemistry, University of Debrecen for the X-Ray diffraction analysis.

This research supported by the Stipendium Hungaricum Scholarship Program.

\section{REFERENCES}

Alam, H.-Khatoon, N.-Raza, M.-Ghosh, P.C.-Sardar, M. (2019): Synthesis and Characterization of Nano Selenium Using Plant Biomolecules and Their Potential Applications. Bio Nano Science, 9(1), 96-104. https://doi.org/10.1007/s12668-0180569-5

Ashwini, S.-Chandrakala, N.-Ravikumar, R.L. (2019): Genetic Variability for Osmotic Adjustment in Pollen Grains and its Association with Field Tolerance to Moisture Stress in Maize Inbred Lines. Current Science, 116(2), 279. https://doi.org/10.18520/cs/v116/i2/279-285

Badade, ZG, M. K.-Narshetty, JG. (2011): Oxidative stress adversely affects spermatogenesis in male infertility. Biomedical Research, 22(3), 323-328.

Bao, P.-Chen, Z.-Tai, R.-Z.-Shen, H.-M.-Martin, F.L.-Zhu, Y.-G. (2015): Selenite-Induced Toxicity in Cancer Cells Is Mediated by Metabolic Generation of Endogenous Selenium Nanoparticles. Journal of Proteome Research, 14(2), 1127-1136. https://doi.org/10.1021/pr501086e

Benko, I.-Nagy, G.-Tanczos, B.-Ungvari, E.-Sztrik, A.-Eszenyi, P.-Prokisch, J.-Banfalvi, G. (2012): Subacute toxicity of nanoselenium compared to other selenium species in mice. Environmental Toxicology and Chemistry, 31(12), 2812-2820. https://doi.org/10.1002/etc.1995

Cavalu, S.-Kamel, E.-Laslo, V.-Fritea, L.-Costea, T.-Antoniac, I.V.-Vasile, E.-Antoniac, A.-Semenescu, A.-Mohan, A.Saceleanu, V.-Vicas, S. (2018): Eco-friendly, Facile and Rapid Way for Synthesis of Selenium Nanoparticles Production, structural and morphological characterisation. Revista de Chimie, 68(12), 2963-2966. https://doi.org/10.37358/RC.17.12.6017

Chen, H.-Yoo, J.-B.-Liu, Y.-Zhao, G. (2011): Green synthesis and characterization of se nanoparticles and nanorods. Electronic Materials Letters, 7(4), 333-336. https://doi.org/10.1007/s13391-011-0420-4

Cruz, D.M.-Mi, G.-Webster, T.J. (2018): Synthesis and characterization of biogenic selenium nanoparticles with antimicrobial properties made by Staphylococcus aureus, methicillin-resistant Staphylococcus aureus (MRSA), Escherichia coli, and Pseudomonas aeruginosa. Journal of Biomedical Materials Research Part A, 106(5), 1400-1412. https://doi.org/10.1002/jbm.a.36347
Fernandes, A.P.-Wallenberg, M.-Gandin, V.-Misra, S.-Tisato, F.Marzano, C.-Rigobello, M.P.-Kumar, S.-Björnstedt, M. (2012): Methylselenol Formed by Spontaneous Methylation of Selenide Is a Superior Selenium Substrate to the Thioredoxin and Glutaredoxin Systems. PLoS ONE, 7(11), e50727. https://doi.org/10.1371/journal.pone.0050727

Fesharaki, P.J.-Nazari, P.-Shakibaie, M.-Rezaie, S.-Banoee, M.Abdollahi, M.-Shahverdi, A.R. (2010): Biosynthesis of selenium nanoparticles using Klebsiella pneumoniae and their recovery by a simple sterilization process. Brazilian Journal of Microbiology, 41(2), 461-466. https://doi.org/10.1590/S151783822010000200028

Galbraith, M.L.-Vorachek, W.R.-Estill, C.T.-Whanger, P D.-Bobe, G.-Davis, T.Z.-Hall, J.A. (2016): Rumen Microorganisms Decrease Bioavailability of Inorganic Selenium Supplements. Biological Trace Element Research, 171(2), 338-343. https://doi.org/10.1007/s12011-015-0560-8

Gangadoo, S.-Stanley, D.-Hughes, R.J.-Moore, R.J.-Chapman, J. (2017): The synthesis and characterisation of highly stable and reproducible selenium nanoparticles. Inorganic and Nano-Metal Chemistry, 47(11), 1568-1576. https://doi.org/10.1080/24701556.2017.1357611

Hageman, S.P.W.-van der Weijden, R.D.-Stams, A.J.M.-Buisman, C.J.N. (2017): Bio-production of selenium nanoparticles with diverse physical properties for recovery from water. International Journal of Mineral Processing, 169, 7-15. https://doi.org/10.1016/j.minpro.2017.09.018

Horikoshi, S.-Serpone, N. (Eds.). (2013): Microwaves in nanoparticle synthesis: Fundamentals and applications. Wiley$\mathrm{VCH}$

Jackman, J.A.-Lee, J.-Cho, N.-J. (2016): Nanomedicine for Infectious Disease Applications: Innovation towards BroadSpectrum Treatment of Viral Infections. Small, 12(9), 11331139. https://doi.org/10.1002/smll.201500854

Joshi, M.-Bhattacharyya, A.-Ali, S.W. (2008): Characterization techniques for nanotechnology applications in textiles. Indian Journal of Fibre \& Textile Research, 33, 304-317.

Kojouri, G.A.-Sadeghian, S.-Mohebbi, A.-Mokhber Dezfouli, M.R. (2012): The Effects of Oral Consumption of Selenium Nanoparticles on Chemotactic and Respiratory Burst Activities of Neutrophils in Comparison with Sodium Selenite in Sheep. 
Biological Trace Element Research, 146(2), 160-166. https://doi.org/10.1007/s12011-011-9241-4

Kora, A.J.-Rastogi, L. (2017): Bacteriogenic synthesis of selenium nanoparticles by Escherichia coli ATCC 35218 and its structural characterisation. IET Nanobiotechnology, 11(2), 179-184. https://doi.org/10.1049/iet-nbt.2016.0011

Lampis, S.-Zonaro, E.-Bertolini, C.-Bernardi, P.-Butler, C.S.Vallini, G. (2014): Delayed formation of zero-valent selenium nanoparticles by Bacillus mycoides SeITE01 as a consequence of selenite reduction under aerobic conditions. Microbial Cell Factories, 13(1), 35. https://doi.org/10.1186/1475-2859-13-35

Li, Q.-Chen, T.-Yang, F.-Liu, J.-Zheng, W. (2010): Facile and controllable one-step fabrication of selenium nanoparticles assisted by 1-cysteine. Materials Letters, 64(5), 614-617. https://doi.org/10.1016/j.matlet.2009.12.019

Li, S.-Shen, Y.-Xie, A.-Yu, X.-Zhang, X.-Yang, L.-Li, C. (2007) Rapid, room-temperature synthesis of amorphous selenium/protein composites using Capsicum аппиит L extract. Nanotechnology, 18, 405101. https://doi.org/10.1088/0957$4484 / 18 / 40 / 405101$

Lin, Z.-H.-Chris Wang, C.R. (2005): Evidence on the size-dependent absorption spectral evolution of selenium nanoparticles. Materials Chemistry and Physics, 92(2-3), 591-594. https://doi.org/10.1016/j.matchemphys.2005.02.023

Pi, J.-Yang, F.-Jin, H.-Huang, X.-Liu, R.-Yang, P.-Cai, J. (2013) Selenium nanoparticles induced membrane bio-mechanical property changes in MCF-7 cells by disturbing membrane molecules and F-actin. Bioorganic \& Medicinal Chemistry Letters, 23(23), 6296-6303. https://doi.org/10.1016/j.bmcl.2013.09.078

Prasad, K.S.-Patel, H.-Patel, T.-Patel, K.-Selvaraj, K. (2013): Biosynthesis of Se nanoparticles and its effect on UV-induced DNA damage. Colloids and Surfaces B: Biointerfaces, 103, 261266. https://doi.org/10.1016/j.colsurfb.2012.10.029

Prasad, R.-Bhattacharyya, A.-Nguyen, Q.D. (2017): Nanotechnology in Sustainable Agriculture: Recent Developments, Challenges, and Perspectives. $\begin{array}{lllll}\text { Frontiers in } \quad \text { Microbiology, } & 8, & 1014\end{array}$ https://doi.org/10.3389/fmicb.2017.01014

Prokisch, J.-Zommara, M. (2011): Process for producing elemental selenium nanospheres (Patent No. US 8003071 B2).

Qin, Y.-Ji, X.-Jing, J.-Liu, H.-Wu, H.-Yang, W. (2010): Size control over spherical silver nanoparticles by ascorbic acid reduction. Colloids and Surfaces A: Physicochemical and Engineering Aspects, 372(1-3), 172-176. https://doi.org/10.1016/j.colsurfa.2010.10.013

Ram, P.-Vivek, K.-Kumar, S.P. (2014). Nanotechnology in sustainable agriculture: Present concerns and future aspects. African Journal of Biotechnology, 13(6), 705-713. https://doi.org/10.5897/AJBX2013.13554

Ramamurthy, Ch.-Sampath, K.S.-Arunkumar, P.-Kumar, M.S.Sujatha, V.-Premkumar, K.-Thirunavukkarasu, C. (2013): Green synthesis and characterization of selenium nanoparticles and its augmented cytotoxicity with doxorubicin on cancer cells. Bioprocess and Biosystems Engineering, 36(8), 1131-1139. https://doi.org/10.1007/s00449-012-0867-1

Shi, L.-Xun, W.-Yue, W.-Zhang, C.-Ren, Y.-Shi, L. (2011): Effect of sodium selenite, Se-yeast and nano-elemental selenium on growth performance, Se concentration and antioxidant status in growing male goats. In Small Ruminant Research. (Vol. 1-96(1), pp. 49-52).
Shi, L.-Xun, W.-Yue, W.-Zhang, C.-Ren, Y.-Liu, Q.-Wang, Q.Shi, L. (2011): Effect of elemental nano-selenium on feed digestibility, rumen fermentation, and purine derivatives in sheep. Animal Feed Science and Technology, 163(2-4), 136142. https://doi.org/10.1016/j.anifeedsci.2010.10.016

Shi, Li-guang-Yang, R.-Yue, W.-Xun, W.-Zhang, C.-Ren, Y.-Shi, L.-Lei, F. (2010): Effect of elemental nano-selenium on semen quality, glutathione peroxidase activity, and testis ultrastructure in male Boer goats. Animal Reproduction Science, 118(2-4), 248-254. https://doi.org/10.1016/j.anireprosci.2009.10.003

Shoeibi, S.-Mashreghi, M. (2017): Biosynthesis of selenium nanoparticles using Enterococcus faecalis and evaluation of their antibacterial activities. Journal of Trace Elements in Medicine and Biology, 39, 135-139. https://doi.org/10.1016/j.jtemb.2016.09.003

Malhotra, S.-Jha, N.-Desai, K. (2014): A Superficial Synthesis of Selenium Nanospheres Using Wet Chemical Approach. International Journal of Nanotechnology and Application (IJNA), 3(4), 7-14.

Sonkusre, P.-Singh Cameotra, S. (2015): Biogenic selenium nanoparticles inhibit Staphylococcus aureus adherence on different surfaces. Colloids and Surfaces B: Biointerfaces, 136, 1051-1057. https://doi.org/10.1016/j.colsurfb.2015.10.052

Sowndarya, P.-Ramkumar, G.-Shivakumar, M.S. (2017): Green synthesis of selenium nanoparticles conjugated Clausena dentata plant leaf extract and their insecticidal potential against mosquito vectors. Artificial Cells, Nanomedicine, and Biotechnology, 45(8), 1490-1495. https://doi.org/10.1080/21691401.2016.1252383

Srivastava, N.-Mukhopadhyay, M. (2015): Green synthesis and structural characterization of selenium nanoparticles and assessment of their antimicrobial property. Bioprocess and Biosystems Engineering, 38(9), 1723-1730. https://doi.org/10.1007/s00449-015-1413-8

Stacey, B.-Nazmul, S.-Aaron, D.-Ipsita, B. (2013): The Spontaneous Formation of Selenium Nanoparticles on Gallic Acid Assemblies and their Antioxidant Properties. The Fordham Undergraduate Research Journal, 1(1)

Sun, K.-Qiu, J.-Liu, J.-Miao, Y. (2009): Preparation and characterization of gold nanoparticles using ascorbic acid as reducing agent in reverse micelles. Journal of Materials Science, 44(3), 754-758. https://doi.org/10.1007/s10853-008-3162-4

Torres, S.K.-Campos, V.L.-León, C.G.-Rodríguez-Llamazares, S.M.-Rojas, S.M.-González, M.-Smith, C.-Mondaca, M.A. (2012): Biosynthesis of selenium nanoparticles by Pantoea agglomerans and their antioxidant activity. Journal of Nanoparticle Research, 14(11), 1236. https://doi.org/10.1007/s11051-012-1236-3

Trabelsi, H.-Azzouz, I.-Ferchichi, T.-Sakly, M.-Abdelmelek, H. (2013): Nanotoxicological evaluation of oxidative responses in rat nephrocytes induced by cadmium. International Journal of Nanomedicine, 3447. https://doi.org/10.2147/IJN.S49323

Vieira, A.-Stein, E.-Andreguetti, D.-Cebrián-Torrejón, G.Doménech-Carbó, A.-Colepicolo, P.-Ferreira, A.M. (2017): "Sweet Chemistry": A Green Way for Obtaining Selenium Nanoparticles Active against Cancer Cells. Journal of the Brazilian Chemical Society. https://doi.org/10.21577/01035053.20170025

Vyas, J.-Rana, S. (2018): Synthesis of selenium nanoparticles using Allium sativum extract and analysis of their antimicrobial property against gram positive bacteria. The Pharma Innovation Journal, 7(9), 262-266. 
Wang, H.-Zhang, J.-Yu, H. (2007): Elemental selenium at nano size possesses lower toxicity without compromising the fundamental effect on selenoenzymes: Comparison with selenomethionine in mice. Free Radical Biology and Medicine, 42(10), 1524-1533. https://doi.org/10.1016/j.freeradbiomed.2007.02.013

Xiong, Y.-Xia, Y. (2007): Shape-Controlled Synthesis of Meta Nanostructures: The Case of Palladium. Advanced Materials, 19(20), 3385-3391. https://doi.org/10.1002/adma.200701301

Xun, W.-Shi, L.-Yue, W.-Zhang, C.-Ren, Y.-Liu, Q. (2012): Effect of High-Dose Nano-selenium and Selenium-Yeast on Feed Digestibility, Rumen Fermentation, and Purine Derivatives in Sheep. Biological Trace Element Research, 150(1-3), 130-136. https://doi.org/10.1007/s12011-012-9452-3

Zhang, J., Wang, X.-Xu, T. (2008): Elemental Selenium at Nano Size (Nano-Se) as a Potential Chemopreventive Agent with Reduced Risk of Selenium Toxicity: Comparison with SeMethylselenocysteine in Mice. Toxicological Sciences, 101(1), 22-31. https://doi.org/10.1093/toxsci/kfm221
Zhang, W.-Chen, Z.-Liu, H.-Zhang, L.-Gao, P.-Li, D. (2011): Biosynthesis and structural characteristics of selenium nanoparticles by Pseudomonas alcaliphila. Colloids and Surfaces. B, Biointerfaces, 88(1), 196-201. https://doi.org/10.1016/j.colsurfb.2011.06.031

Zhang, Y.-Li, X.-Huang, Z.-Zheng, W.-Fan, C.-Chen, T. (2013): Enhancement of cell permeabilization apoptosis-inducing activity of selenium nanoparticles by ATP surface decoration. Nanomedicine: Nanotechnology, Biology and Medicine, 9(1), 74-84. https://doi.org/10.1016/j.nano.2012.04.002 
